\title{
ENTRE EL AYER OCUPADO Y EL MAÑANA "LIBERADO". LAS CONSECUENCIAS DEL PERÍODO 1940-1944 SOBRE LA POLICÍA Y LA SOCIEDAD POLICIAL FRANCESAS*
}

\section{Between yesterday occupied and tomorrow "liberated". The consequences of the period 1940-1944 on the French police and police society}

\section{Jean-Marc Berlière}

Université de Bourgogne - CESDIP (Centre de Recherches Sociologiques sur le Droit et les Institutions Pénales). berliere@,cesdip.fr

Recibido: 18-05-2020- Aceptado: 03-11-2020

\begin{tabular}{|c|c|}
\hline $\begin{array}{l}\text { Cómo citar este artículo/Citation: } \\
\text { Jean-Marc Berlière, "Entre el ayer ocupado y el mañana } \\
\text { "liberado". Las consecuencias del período 1940-1944 } \\
\text { sobre la policía y la sociedad policial francesas", Hispania } \\
\text { Nova, } 19 \text { (2021): } 661 \text { a } 690 \text {. }\end{array}$ & $\begin{array}{l}\text { Copyright: C HISPANIA NOVA es una revista } \\
\text { debidamente registrada, con ISSN 1138-7319 y Depósito } \\
\text { Legal M 9472-1998. Los textos publicados están -si no se } \\
\text { indica lo contrario- bajo una licencia Reconocimiento-Sin } \\
\text { obras derivadas 3.0 España de Creative Commons. Puede } \\
\text { copiarlos, distribuirlos y comunicarlos públicamente } \\
\text { siempre que cite su autor y la revista y la institución que } \\
\text { los publica y no haga con ellos obras derivadas. La licencia } \\
\text { completa pe puede consultar a en: } \\
\text { http://creativecommons.org/licenses/by-nd/3.0/es/deed.es }\end{array}$ \\
\hline
\end{tabular}

Resumen: Aunque breve (1940-1944), el período de la ocupación alemana y el gobierno de Vichy constituye un periodo decisivo tanto para la Policía como para la sociedad "policial" francesas. La estatalización, la centralización, la profesionalización y la militarización que caracterizan a la Policía francesa datan de este momento, junto con la recurrente imagen negativa de las misiones que llevó a cabo, en el contexto de las políticas de exclusión y represión impuestas por el régimen de Pétain y la colaboración instaurada con la ocupación nazi.

Palabras clave: Ocupación, Policía, Régimen de Vichy.
Abstract: Although brief (1940-1944), the period of German occupation and Vichy government constitutes a decisive period for French police institution and society. State control, centralization and professionalization characterizing today the French police date back to this period, together with a dark recurrent image linked to the missions accomplished by the police, within the context of policies of exclusion and repression forced upon by Pétain government and collaboration established with Nazi occupiers.

Keywords: Occupation, Police, Vichy Regime. 


\section{¿UNA POLICÍA ATRAPADA?}

Un desastre militar sin precedentes, las condiciones del armisticio firmado el 22 de junio de 1940, la ocupación de cerca de dos terceras partes del territorio por parte del vencedor, la república desmantelada y la creación, el 10 de julio de 1940, de un «Estado francés» autoritario, antidemocrático y liberticida, sumergieron en el verano de $1940 \mathrm{a}$ los servicios de policías y sus agentes en unas circunstancias muy particulares causadas por los intereses, cálculos y segundas intenciones de los tres interlocutores presentes: el ocupante alemán, el nuevo régimen recién nacido en Vichy y la propia institución policial.

Desprovisto de gran parte de los instrumentos habituales de un estado soberano, esforzándose por que se reconociera la realidad de su poder frente al ocupante y preocupado por afirmar su soberanía y autonomía ante el vencedor, el gobierno instalado en Vichy vio en la policía el uso de un poder soberano que el ocupante le concedía a cuentagotas. La policía, considerada en el entorno del mariscal Pétain como un instrumento de la restauración nacional y de la supervivencia del Estado, fue además el instrumento principal de una colaboración estatal cuyo gobierno esperaba un lugar preferente para Francia en una Europa que imaginaban por mucho tiempo dominada por los nazis. El nuevo poder necesitaba a la policía por numerosas razones. El Estado francés era un régimen nuevo que debía afirmar su soberanía a través de la dirección de la policía: instrumento tradicionalmente preciado en la panoplia del gobierno y señal esencial de poder. Quien «tuviera» la policía era el verdadero dueño del poder. El régimen de Pétain era autoritario y antidemocrático: la policía y la justicia eran esenciales para imponer el nuevo orden y hacerlo respetar.

El nuevo régimen estaba dirigido por hombres procedentes en su mayor parte de la derecha antirrepublicana que nunca habían ejercido responsabilidades y se encontraban fascinados por los poderes - a menudo sobrestimados - que atribuyen a la institución. El fantasma de una «policía política republicana»y sus «crímenes» ${ }^{1}$ estaba

\footnotetext{
* Esta contribución representa una introducción al tema basada en el último libro del autor, Jean-Marc Berlière, Polices des temps noirs (Paris, Perrin, 2018). Texto traducido por Sonia Vasconcelos y revisado por Alejandro Pérez-Olivares.
} 
muy presente para los hombres que, en su oposición radical a la República, desde el caso Dreyfus habían vivido continuadamente en la psicosis y obsesión por los poderes ocultos de una policía «podrida» y «corrompida», «muralla de barro y sangre» de un gobierno de «ladrones y asesinos» servido por «hombres sangrientos», una guardia pretoriana que asimilaban al «ala andante y asesina de la Masonería» como hacía Léon Daudet en sus panfletos ${ }^{2}$.

El nuevo estado, portador de un proyecto ideológico- la «Revolución Nacional» — basado en el orden, la exclusión y la represión, dio a la policía una importancia comparable a la que tiene en todos los regímenes dictatoriales: no solo es indispensable para el mantenimiento de un nuevo orden sacralizado, la represión de las libertades suprimidas, y la política de exclusión y represión de la «anti-Francia» judíos, extranjeros, masones, «rojos »— que la caracteriza, sino que, desde el principio, fue considerada por el nuevo poder como instrumento primordial y pilar esencial de una restauración nacional cuya necesidad era urgente e imperiosa por causa de la derrota.

Al disponer solo de dos instrumentos de soberanía - la policía y la justicia- el Estado francés tenía la preocupación constante de que «la represión se ejerza por manos francesas, brazos franceses y cabezas francesas ${ }^{3} \gg$ como proclamó, el 21 de enero de 1942 en la jura de los policías de París, el Secretario de Estado de Interior Pierre Pucheu. Los hombres en el poder siempre ejercieron -o quisieron ejercer- todas las prerrogativas en estos dos ámbitos y, en lo posible, en la totalidad del territorio, con el objetivo de evitar la «humillación» de ver al ocupante dar órdenes o, peor aún, sustituir a la administración francesa. Aquí encontramos todo lo paradójico de los gobiernos de Vichy: para probar su soberanía y demostrar al vencedor que Francia merecía un lugar principal en la nueva Europa que imaginaban por mucho tiempo dominada por Alemania, el Estado francés iba a reivindicar constantemente el ejercicio autónomo de la represión aun cuando la misma sirviera a los intereses del ocupante.

Podemos concebir en estas condiciones la relevancia estratégica, el desafío que representaban las fuerzas del orden para los hombres llegados al poder. Querían una

\footnotetext{
${ }^{1}$ Louis Ducloux, Du chantage à la trahison (París, Gallimard, 1955).

${ }^{2}$ Léon Daudet, La police politique et ses crimes (París, 1934) y Magistrats et policiers (París, 1935), passim.

${ }^{3}$ Marc-Olivier Baruch, Servir l'Etat français (París, Fayard, 1997).
} 
policía leal, fiel, numerosa, moderna, bien equipada, eficaz, profesional, centralizada, bien controlada por el gobierno, ideológicamente segura. Como cabe imaginarse, la que heredaron apenas les satisfacía ni les inspiraba confianza. La importancia que querían otorgar a la policía era comparable con la desconfianza que sentían respecto al instrumento que heredaban de la república pues, a sus ojos, adolecía de fallas graves o incluso taras que la hacían incompatible con la función a la que estaban destinada. ¿Cómo usar una institución a la que durante el periodo anterior a la guerra acusaron constantemente de ser «una checa oculta al servicio de la masonería»? ¿Cómo conformarse con una administración que se había mostrado desesperadamente leal al servicio de la república y con policías que, desde el caso Dreyfus hasta el Frente Popular, persiguieron con determinación y eficacia a muchos de los hombres ahora en el poder? Por tanto, sentían una gran desconfianza - es un eufemismo- alimentada por temor y rencor respecto a la Prefectura de Policía y más aún con respecto a los «señores sangrientos» de esa «asociación de malhechores» que constituían, según L. Daudet y sus amigos, la «Seguridad general llamada nacional». Del mismo modo, la organización general de la policía heredada de la Tercera República no les producía una satisfacción mayor. Tenía un carácter municipal y su organización tan fragmentada hacía que no se pudiera adaptar al uso que quería darle un régimen autoritario: tanto el reclutamiento como la organización y las funciones (a pesar de la tímida política de estatalización emprendida por la Tercera República) se escapaban al poder central en beneficio de alcaldes o del Consejo Municipal de París.

Por esos motivos el nuevo régimen se lanzó, desde el otoño de 1940, a una política muy activa de reformas destinadas a crear un instrumento que respondiera a sus necesidades y exigencias y estatalizó, multiplicó, centralizó, modernizó y especializó todo el aparato policial. Esta reorganización fue el objeto de una obra legislativa considerable.

\section{NUEVO RÉGIMEN, NUEVA POLICÍA}

Según la visión de las nuevas personas en el poder, se trataba en primer lugar de reformar una organización policial que escapaba en gran parte al Estado y cuya fragmentación en centenares de policías municipales con competencias en áreas 
geográficas limitadas, sin vínculos orgánicos, estaba lejos de satisfacer a un poder autoritario. Uno de los objetivos esenciales del gobierno consistió en estatalizar, centralizar y unificar la «polvareda de policías» heredada y hacer de la policía un instrumento eficaz y moderno al servicio del gobierno. Entre el 19 de abril y el 17 de julio, el gobierno aprobó once «leyes» y decretos de reforma de la organización de la policía. Sus palabras clave: unificación, estatalización, centralización, racionalización, multiplicación de los efectivos y formación ${ }^{4} \ldots$

Reivindicado y esperado por muchos policías, el régimen de policías del Estado que existía para algunas ciudades —-Lyon, Marsella, Niza, etc.- fue ampliado a todas las ciudades de más de 10000 habitantes y a cierto número de circunscripciones social o políticamente «sensibles». En estas ciudades los alcaldes perdieron sus poderes sobre la policía, que pasaron a los prefectos e «intendentes de policía» que dirigían, en cada una de las 20 regiones creadas, «policías regionales de Estado» (PRE). Constituían la etapa regional de las grandes direcciones nacionales de la Secretaría General de la Policía lo que, de cierta forma, suponía el renacimiento del antiguo Ministerio de la Policía general de Fouché definitivamente desaparecido en 1853. El mismo día, otros dos textos proyectaban la creación de una Escuela Nacional Superior de Policía para la formación de comisarios e inspectores, y de una fuerza civil específica de mantenimiento del orden -los Grupos Móviles de Reserva (GMR)- uniformada y acuartelada, para intervenir como refuerzo de las fuerzas de seguridad pública de los cuerpos urbanos: una creación y una militarización de facto que el gobierno tendrá muchas dificultades para llevar hasta la Zona Ocupada debido a las reticencias y desconfianza de los alemanes, que lo veían como un intento de sobrepasar los límites impuestos por las convenciones del armisticio.

El decreto del 13 de mayo de 1941 instauró, en cada una de las 20 regiones creadas, una estructura centralizada de los servicios. Los prefectos regionales instaurados por el mismo grupo de leyes estaban a cargo de la policía de la región, y con la asistencia de un intendente de policía controlaban todas las fuerzas de policía. Sobre esta estructura regional existía una Dirección general de la Policía nacional bajo

\footnotetext{
${ }^{4}$ Journal Officiel De L'état Français N 1803 — LOI du 23 avril 1941 « portant organisation générale des services de police en France». El desarrollo en detalle y el análisis se encuentran en Jean-Marc Berlière, Polices des temps noirs (París, Perrin, 2018).
} 
la autoridad del Secretario General de la Policía. La instauración de las policías regionales de Estado fue mucho más lenta y dificultosa de lo previsto. Los medios llegaron tarde, el reclutamiento estuvo lejos de ser todo lo exitoso que se esperaba y los alemanes eran reacios a su extensión en territorio ocupado: hasta el 27 de octubre de 1942 no se estatalizaron las policías de ocho regiones de la zona ocupada y los alemanes no dieron hasta octubre de 1943 la autorización de continuar el proceso en la zona sur, donde se había interrumpido desde su ocupación, en noviembre de 1942, tras el desembarco angloamericano en África Septentrional. Por otro lado, tomemos noticia de que la policía parisina - la Prefectura de Policía (PP) — quedaba totalmente al margen de esta reforma. Como en el caso de la Tercera República o de los regímenes precedentes, los sucesivos gobiernos de Vichy no pudieron tampoco alterar el estatus particular de París en el ámbito policial. No faltaba sin embargo la desconfianza respecto a la policía parisina, presentada en los diferentes informes como «entregada»a los sindicatos, llena de «criaturas» de Léon Blum, sometida a la masonería y llena de judíos secuaces ¡del Frente Popular! Pero a pesar de las sucesivas tentativas de Pierre Pucheau $^{5}$, Ministro de Interior, en otoño de 1941, y después de Joseph Darnand, Secretario General para el Mantenimiento del Orden, en la primavera de 1944, ya fuera para suprimir la Prefectura de Policía, o para anexionarla más firmemente al dispositivo general y someterla de forma más directa a su autoridad, la policía parisina conservó su originalidad y organización propia.

Semejante reorganización -especialmente la estatalización de las policías municipales- precisaba un incremento masivo de los efectivos en los que Vichy esperaba un cambio de mentalidad, así como una transformación profunda del mundo policial. Se acompañó de ventajas materiales -salarios, diversas indemnizaciones y primas, renovación de los locales, nuevos uniformes, medios modernos de comunicación- para atraer a nuevos efectivos — «sin pasado político» - y para instituir un "cuerpo de élite" que el Estado francés quería como uno de los pilares de la obra de saneamiento y enderezamiento que se tenía marcada como objetivo. Estas reformas, la instauración de una Policía nacional a la vez racional, centralizada, unificada y jerarquizada, la voluntad de modernización, la preocupación por la formación y

\footnotetext{
${ }^{5}$ Sobre este personaje complejo y contradictorio, Cf. Gilles Antonowicz, L'énigme Pierre Pucheu (París, Nouveau-Monde éditions, 2018).
} 
profesionalización de los policías a los que se da ventajas pecuniarias sustanciales, colmó las expectativas de un mundo que por fin conseguía algunas de las reformas que, desde hacía medio siglo, pedían sin descanso sus organizaciones corporativas. Al realizar la obra de estatalización y centralización tímidamente esbozada-desde los principios de siglo, el Estado francés parecía situarse en la continuidad de la Tercera República de la que iba a conservar, de forma no menos paradójica, parte de su personal.

\section{¿NUEVA POLICÍA, NUEVOS POLICÍAS?}

Esta continuidad no deja de sorprender al conocer el ánimo de los dirigentes y los diferentes clanes que poblaban los ministerios y antecámaras de Vichy. ¿Cómo y por qué personas procedentes en su mayoría de la derecha antirrepublicana, y todas con cuentas que reclamar a la policía de la República, pudieron conservar a los hombres a los que habían combatido, en ocasiones duramente, en el periodo anterior a la guerra?

En primer lugar, por necesidad. Como escribía Louis Ducloux ${ }^{6}$, antiguo director de la Policía Judicial de la Seguridad Nacional, y por ese motivo diana favorita de l'Action française y de Léon Daudet: «En plena debacle, en plena confusión de los servicios administrativos, en plena evolución política, el gobierno de facto se encuentra en presencia de una enorme máquina y no conoce ni su estructura, ni su manejo [...] No se puede hacer casi nada sin el antiguo cuerpo de policía». Vichy conservó a los hombres de la Tercera República del mismo modo que supo usar algunas leyes, lo que permitió que muchos policías creyesen que continuaban en el mismo trabajo. La continuidad a la cabeza de la Prefectura de Policía hasta febrero de 1941 de Roger Langeron, prefecto de policía desde 1934 y cuyas vinculaciones políticas y masónicas nadie podía ignorar, era algo que tranquilizaba a más de un agente de policía parisino respecto a la continuidad administrativa y la aparente buena voluntad del nuevo régimen. Se puede decir lo mismo de Aimé Bussière, antiguo director de la Seguridad Nacional, de Marx Dormoy (Ministro de Interior socialista), nombrado prefecto de policía en 1942, o René Bousquet, Secretario General de la policía y el prefecto más joven de la Tercera República, muy ligado a los radicales-socialistas del sudoeste, y que

\footnotetext{
${ }^{6}$ Op. cit. 
fue puesto a cargo del "fichero central" por el Ministro de Interior del Frente Popular, Roger Salengro. Es aún más claro en el caso de un hombre del terreno como Félix Buffet, jefe de la Brigada Móvil de Clermont-Ferrand, el mismo que había llevado la investigación contra la rama de Clermont de «la Cagoule $^{7}$ » y al que Laval y Bousquet nombraron director de la Policía de seguridad de Vichy.

Estas vinculaciones esclarecen una continuidad policial que pudo perturbar a más de un policía. La conservación por necesidad de la mayor parte de los policías, en su mayoría fieles a su cultura de obediencia y respeto al gobierno legal, no impidió sin embargo que se tomaran precauciones. Para asegurar la dedicación y la fidelidad de los funcionarios de policía, el Estado francés, como se hizo durante el Segundo Imperio, instituyó un juramento personal de fidelidad al Jefe del Estado. Se impuso primero a la jerarquía por medio de la Acte constitutionnel del 27 de enero de1941, después a la totalidad de los funcionarios por el acta del 4 de octubre de 1941. El texto: "Jjuro fidelidad a la persona del Jefe del Estado en todo lo que ordene, en el interés del servicio y del orden público, por el bien de la patria" ${ }^{2}$, fue un peso real aunque difícilmente evaluable en la actitud de muchos policías, que lo recordaron en la Liberación para justificar su fidelidad al «gobierno de hecho»y su obediencia a las órdenes que les dio.

Estas medidas no excluían la amenaza ni el rigor. Asegurar la lealtad absoluta del ámbito policial parecía imponer la eliminación en lo posible de los elementos demasiado marcados por su afiliación a partidos de izquierda, al sindicalismo o la masonería. El Estado francés, como otros regímenes anteriores, se encontró ante el problema de la depuración policial. Era algo que exigían enérgicamente entre las filas de varios componentes de la derecha presentes en Vichy y los extremistas parisinos. Muchos reclamaban medidas severas contra los funcionarios cuya lealtad y fidelidad a la «démocrassouille» ${ }^{9}$ habían podido medir en numerosas ocasiones. La originalidad de la política seguida por Vichy en este ámbito se debe en parte al hecho de que, a pesar de

\footnotetext{
${ }^{7}$ De nombre real OSARN (Organización Secreta de Acción Revolucionaria Nacional) la cual, armada por el fascismo italiano, organizó atentados y asesinatos políticos y fomentó un golpe de estado militar en 1937.

${ }^{8}$ «Je jure fidélité à la personne du chef de l'État pour tout ce qu'il commandera dans l'intérêt du service et de l'ordre public, pour le bien de la patrie»

${ }^{9}$ Término despectivo para referirse al sistema de la III República, formado por las palabras «démocratie» y «souille». Puede traducirse por «democrasucia». Nota de Alejandro Pérez-Olivares.
} 
que el régimen se dotó de forma efectiva de los medios, con la ley del 17 de julio de $1940^{10}$, y después con el decreto del 21 de septiembre de $1942^{11}$, de relevar a cualquier funcionario público de sus funciones -«a pesar de disposiciones legislativas o reglamentarias en sentido contrario» y «sin ninguna otra formalidad»-, en la práctica pudo y tuvo que evitar un depuración profunda.

Sin embargo, la voluntad de depurar la policía de los elementos «subversivos» se manifestó muy tempranamente: una circular del Ministerio de Interior dirigida el 22 de septiembre a todos los prefectos pedía señalar -para aplicarles la reciente ley del 17 de julio- a todos los funcionarios de la Seguridad Nacional en servicio en su departamento cuyas maneras de prestación no fueran satisfactorias, bien por ser «dudosas» en el plano político o nacional, bien por estar «prematuramente fatigados». No disponemos de ninguna estadística completa, precisa y fiable de la depuración de la policía por parte de Vichy, pero las cifras conocidas llevan a concluir que hubo una depuración real, aunque muy moderada. Una moderación que parecía traducir el propio interés de un poder que necesitaba la experiencia profesional de los policías de oficio, especialmente en el periodo precedente a la reconstrucción de la policía que quería llevar a cabo. Podemos pensar igualmente que traducía la lealtad y fidelidad -algunos dirán la neutralidad o incluso la prudencia- de los policías convertidos en expertos de la explotación de su profesionalidad en tanto que escudo.

Aunque esta primera tanda de jubilaciones y exclusiones fue moderada, la amenaza de la revocación contenida en la ley del 17 de julio de 1940 constantemente prorrogada funcionó como una espada de Damocles suspendida sobre los policías con pasado político, ideas o relaciones, con una supuesta falta de celo o lealtad, lo que les convertía en excluidos con aplazamiento. La amenaza de la revocación, el miedo a los alemanes que, rápidamente, deportaron a algunos policías, fueron suficientes para asegurar la docilidad del mundo policial. El nuevo régimen pudo y creyó poder evitar una limpieza profunda de la policía, tanto más por la simpatía y fidelidad suscitada por muchas de sus medidas y porque la sociedad policial había de estar profundamente reformada gracias a las reformas de la primavera de 1941. La estatalización de las

\footnotetext{
${ }^{10}$ Journal officiel de la République française de 18 julio de1940.

${ }^{11}$ Journal officiel de l'Etat Français, n²27, 21 y 22 de septiembre 1942
} 
policías municipales tuvo como consecuencia el aumento, en una gran proporción, de efectivos de policía ampliamente renovados en tanto que parte del personal de las antiguas policías municipales no fue reintegrada en las nuevas estructuras de las policías regionales de Estado, generalmente con el pretexto de su incompetencia profesional o de criterios -moralidad, edad, salud, aptitudes físicas- que no correspondían a las reglas del nuevo reclutamiento. Una práctica que puede asemejarse a una depuración camuflada, pero que es difícil de medir, por lo que conviene matizar la importancia de esta renovación considerando las dificultades reales en el reclutamiento -de tipo cualitativo y cuantitativo- experimentadas por las policías regionales de Estado, aunque fueron muy promocionadas por medio de anuncios. La falta de candidatos, debido a los salarios que se creían demasiados bajos, a la imagen poco valorada, a las misiones impopulares y peligrosas, a las condiciones de trabajo poco atractivas y horarios muy cargados, vino a agravarse por la preocupación de los prefectos regionales de privilegiar a los elementos sanos" en el plano político. Por ese motivo los puestos ofrecidos nunca fueron cubiertos completamente en la mayor parte de regiones y ciudades.

Ante un poder que usaba con ellos tanto la adulación como la amenaza, el llamamiento al deber profesional y al respeto de la ley, ¿cómo reaccionó el ámbito policial, el antiguo y el nuevo? El desconocimiento de las fuertes tendencias de la historia y del pasado de la institución, una historiografía pintada con leyendas rosas o negras, hace que en general se olvide que el periodo de la ocupación (1940-1944) representó para el conjunto de los policías una oportunidad: la de avanzar en las antiguas reivindicaciones al tiempo que se solucionaban algunos conflictos internos y viejas cuentas externas. Comprender las reacciones, la actitud, las derivas de la institución, y especialmente el naufragio de los principios democráticos penosamente adquiridos, supone una comprensión interna de una historia administrativa compleja y de una sociedad impulsada por una cultura específica y unos intereses propios. A las evidentes ventajas de las reformas de 1941 -en términos de primas, estatus, medios, poderes y respeto-, a los espectaculares ascensos que recompensarán el celo y la actividad de ciertos policías, al temor que suscitan por un lado las órdenes alemanas y, por otro, la amenaza permanente de la revocación agitada por la jerarquía, no podemos olvidar añadir el peso de las circunstancias particulares. Las cláusulas del armisticio que dio a Alemania los derechos de la potencia ocupante y por tanto fuerza de ley a sus 
ordenanzas, la existencia de un gobierno legal, el respeto que su jefe —un Mariscal de Francia - inspiraba a los policías mayormente reclutados entre antiguos militares, la política de colaboración de Vichy, su proyecto de "Revolución Nacional", dieron a Francia un estatus único entre los de los países vencidos. Atrapada en la trampa de su propia cultura de obediencia, pero también en intereses corporativos y una «sensibilidad» profesional que le hacía compartir aversiones comunes con sus nuevos jefes - xenofobia, anticomunismo — , la policía, símbolo a la vez de la legitimidad y las prerrogativas de un Estado soberano, herramienta al servicio de una política específica y moneda de cambio con un ocupante que no tenía, por su parte, más objetivo que el de aprovecharse de la ocasión y usar con el menor coste posible un auxiliar inesperado, fue llevada a desempeñar un papel que conviene ubicar en el contexto de las sucesivas políticas conducidas por el régimen. Y, en primer lugar, una inédita situación de competencia en el uso de la fuerza...

\section{LA COMPETENCIA DE LAS «POLICÍAS DE OCASIÓN»}

Junto a las medidas tomadas para reformar y renovar tanto la policía como el "mundo policial" y asegurarse, mediante una dosis eficaz de amenazas y ventajas, la fidelidad de la administración policial, entre los hombres del nuevo poder se pensó primero, sin abandonar nunca la idea, en crear sus propias policías, en tanto que no creían que fuera posible obtener de los policías profesionales la lealtad y entusiasmo suficientes, especialmente en la realización de las tareas específicas que se les querían confiar.

"Vichy estaba lleno de policías de ocasión". Al describir la "jungla" de la capital del Estado francés, el comisario J. Belin observa la aparición de esas "otras policías" cuyo ejemplo tipo lo encuentra en el CIE («Centro de Información y Estudios» y sus «Grupos de protección», los GP): una «policía anexa muy bien armada y de gran movilidad», creada en septiembre de1940 por el coronel Groussard, un militar próximo a los entornos de la extrema derecha, con el pretexto de proteger a un gobierno atormentado por la obsesión del peligro comunista y que confiaba solo relativamente en una policía que tenía «mucho que hacerse perdonar». Formadas por "esbirros", entre ellos "muchos delincuentes con antecedentes", situados "bajo la autoridad del terrorista Méténier", los Grupos de protección "parecían una banda de aventureros" añade Belin, 
que describe el Centro de Información y Estudios, cuyo brazo armado lo formaban los GP, como una "agrupación de chivatos y cagoulards" ${ }^{12}$. Un análisis finalmente confirmado por Groussard, quien reconoció en sus memorias: «El tiempo acuciaba y no teníamos muchas opciones [...] de modo que, cierto número de elementos indeseables entraron en nuestras filas».. ${ }^{13}$

A pesar de su efímera existencia, el CIE, por sus misiones, métodos y personal, era un antecedente de las oficinas policiales que el gobierno de Vichy desarrolló para intentar paliar la indolencia que, según los partidarios de la Revolución Nacional, mostraban los servicios oficiales en el nuevo tipo de misiones represivas que imponía la lucha contra las maniobras «antinacionales». El CIE constituyó la cuna del tríptico Servicio de Policía de Sociedades Secretas (SPSS), Policía para las Cuestiones Judías (PQJ, por sus siglas en francés), Servicio de Policía Anticomunista (SPAC) - creado contra la "anti-Francia" en otoño de 1941 por el Secretario de Estado de Interior, P. Pucheu. Este último, obsesionado por confiar las misiones represivas a "manos y brazos franceses" había imaginado, al desconfiar de una policía sospechosa para él de seguir siendo demasiado fiel a los principios republicanos, la posibilidad de crear policías supletorias cuyo fanatismo le parecía la mejor garantía de lealtad y eficacia. También preocupado por defender las prerrogativas del Estado francés, pero procediendo él mismo de la administración, R. Bousquet, nombrado por Laval para la Secretaria General de la Policía en abril de 1942, adoptó otra política. En su empeño constante dentro de su preocupación por la legalidad formal, la centralización y la profesionalización que respondía perfectamente a su recorrido y ambiciones personalespor hacer reconocer su autoridad sobre todos los servicios de policía, inició la empresa de librar a la Policía Nacional de esas oficinas. Pensaba que eran ya inútiles, así como perjudiciales y peligrosas por el sometimiento ideológico a los nazis, el fanatismo de sus miembros, y sus métodos y abusos cuyo descrédito recaía sobre la administración que él

\footnotetext{
12 «Cagoulard» significa, literalmente, « encapuchado », pero el término hace referencia al "Comité Secreto de Acción Revolucionaria" (CSAR) o a la "Organización Secreta de Acción Revolucionaria Nacional" (OSARN) Nota de Alejandro Pérez-Olivares.

${ }^{13}$ Sobre el CIE et las «policías de ocasión» Cf. Jules Belin, Trente ans à la Sûreté Nationale (París, Bibliothèque France Soir, 1950); Georges Groussard, Service secret 1940-1945 (París, La Table Ronde, 1964); Jean-Marc Berlière, Polices des temps noirs, 201 y siguientes.
} 

francesas

dirigía. Pero las misiones, los métodos de estas «policías laterales» no dejaron de tener consecuencias en la deriva que adquirieron después los servicios de policía oficiales.

\section{LA DERIVA DE LAS MISIONES Y LOS MÉTODOS}

Para marginalizar esos servicios, dejarlos sin razón de ser, competir con sus resultados y dar a la policía una autonomía de acción ante el ocupante que satisficiera su sentimiento nacional y sus propias ambiciones, Bousquet restó importancia al precio a pagar, que consistía en aplicar directamente, y con una eficacia que los pusiera a salvo de cualquier crítica, no sólo la represión de las «maniobras antinacionales» y el «terrorismo», es decir de la Resistencia, sino la represión antijudía impuesta por los alemanes y la legislación autóctona francesa aplicada desde octubre de 1940. El Estado francés creía afirmar su soberanía y la corporación municipal su monopolio; el precio pagado fue el de una deriva importante de sus misiones y prácticas que siguió afectando desde entonces a la institución en términos de imagen y descrédito. Recordemos los naufragios más espectaculares.

La participación de la Policía Judicial en la represión de las «maniobras antinacionales», muestra los límites del «escaparate» de modelo republicano de policía que Clemenceau había querido formar ${ }^{14}$. Las brigadas móviles regionales de policía judicial, creadas en 1907 - «la única policía que una democracia puede reconocer», según su creador- vieron cómo cambiaba considerablemente la naturaleza de sus misiones. Integradas en la Dirección de Policía de Seguridad confiada al comisario Buffet, antiguo miembro de las brigadas móviles ascendido a director general, fueron muy utilizadas contra las "maniobras antinacionales" que solo tenían relaciones formales con el crimen y el bandidismo. Esta evolución culminó con la creación en su seno de las Secciones regionales de asuntos judiciales con origen político que se transformarían unos meses después en las Secciones de asuntos politicos (SAP). Cada Servicio regional de policía contaba con una. En cooperación con el Servicio de Represión de las maniobras antinacionales (SRMAN) que siguió al SPAC o impulsadas por sus éxitos y la competencia, estas secciones provocaron daños considerables, esencialmente en la lucha anticomunista.

\footnotetext{
14 Jean-Marc Berlière, Naissance de la police moderne (París, Perrin, 2011).
} 
La Brigada Especial (BS, por sus siglas en francés) anticomunista de la Dirección de Informaciones Generales (a partir de ahora, IG) de la Prefectura de Policía fue reforzada en enero de 1942, con una "BS2" antiterrorista. Cada una contaba con un centenar de hombres -cuyo celo era estimulado sin cesar por los mandos jerárquicos, ventajas en la carrera y primas importantes-, usaban ficheros e informaciones de la primera sección de las IG, y realizando vigilancias y seguimientos de varias semanas e incluso meses, los inspectores de las BS de las IG debían hacer estragos en las filas del partido clandestino. Sin embargo, no podemos olvidar los cometidos por las Brigadas Especiales de Intervención (BSI, por sus siglas en francés) de la Policía municipal de París: los guardianes de la paz, familiarizados con sus barrios y habitantes, formaron un recurso eficaz en la lucha contra los "comuni-terroristas"15.

Esta lucha, a pesar del cambio de su naturaleza y método, se correspondía - si bien con otros medios y distintas consecuencias- con una tradición policial antigua que parecía prolongar aquella desarrollada contra los "moscoutaires" ${ }^{16}$ desde la década de 1920, pero la situación creada por la legislación antisemita de Vichy y las ordenanzas alemanas quedaban en cambio fuera de cualquier tradición y esta-inédita represión racial afectó a todos los servicios. En la circular que anunciaba a los prefectos regionales la supresión de la $\mathrm{PQJ}^{17}$, en el verano de 1942, R. Bousquet había precisado que «las operaciones judiciales y especialmente los registros necesarios en aplicación de la legislación sobre los Israelitas, serán efectuados por funcionarios de la Policía nacional.» Jean Leguay, delegado de Bousquet para la zona ocupada precisó a Helmut Knochen, jefe de la Sipo-SD (Sichereitspolizei y Sichereitsdienst ${ }^{18}$ ): «De ahora en adelante, todas las operaciones de policía propiamente dichas (arrestos, indagaciones,

\footnotetext{
15 Tenemos un ejemplo de la eficacia de la lucha anticomunista realizada por la Dirección de Informaciones Generales de la Prefectura de Policía y sus «brigadas especiales» en Jean-Marc Berlière y Franck Liaigre, Liquider les traîtres (Paris, Robert Laffont, 2007).

16 «Partidarios de Moscú », literalmente, seguidores de la revolución soviética de 1917. Nota de Alejandro Pérez-Olivares.

${ }^{17}$ « Police aux Questions Juives », agencia encargada específicamente de la persecución de la población judía en territorio francés. Nota de Alejandro Pérez-Olivares

${ }^{18}$ Sobre los servicios represivos alemanes, véase Jean-Marc Berlière, Polices des temps noirs, , 1105 y siguientes. La Sipo-SD ("Policía de Seguridad") era la agencia encargada de perseguir los delitos de tipo político. Una de sus oficinas fue la Gestapo. Nota de Alejandro Pérez-Olivares.
} 

francesas

registros, etc.) relativas a la aplicación de la reglamentación contra los judios solo podrán ser efectuadas por los funcionarios de policía. ${ }^{19}$

Siempre preocupado por no dejar escapar ni una parcela de la represión, el Secretario General situaba de este modo la gestión de la "cuestión judía" a cargo de la policía francesa. En esta inusual misión, a esta policía le iba a ir bien y mejor aún por la emulación tradicional entre servicios que iba a operar con fuerza, como muestra el ejemplo de la Prefectura de Policía.

Desde la «Subdirección de Extranjeros y Judíos» a cargo de las fichas, hasta los guardianes de la paz a cargo de arrestos basados en fichas y del control en la vía pública del respeto a las reglas impuestas a los judíos, toda la Prefectura estuvo implicada en esta misión, también la prestigiosa PJ parisina, el «36» quai des Orfèvres ${ }^{20}$. Un Servicio de Asuntos Judios, vinculado en 1943 a la Dirección de la Policía Judicial, fue confiado a un comisario delegado en las funciones de director-adjunto de la PJ de la PP. El «servicio de Permilleux», según el nombre de su jefe - que agrupó un servicio activo y la antigua subdirección de asuntos judíos - recibía las delaciones, informaciones de los servicios de la Comisaría General de la Cuestión Judía (CGQJ, por sus siglas en francés) y de los alemanes y realizaba directamente indagaciones y arrestos. Multiplicando sus operaciones, establecía asimismo los procedimientos legales para los desplazamientos al campo de Drancy de los judíos que le entregaban los esbirros de la Sección de Investigación y Control (SEC, por sus siglas en francés) o los servicios alemanes. Ni las SS, ni los antisemitas del CGQJ podrían acusar de pasividad o debilidad a un servicio que este comisario de delegaciones judiciales estimuló constantemente con instrucciones precisas y dirigió sin afectación emocional: "Corresponde desde ahora a la Prefectura de Policía asegurarse de la ejecución de las medidas de policía ordenadas por las autoridades de ocupación. La policía francesa no tiene que entrar a juzgar, ejecuta las órdenes dadas."

La Dirección de Informaciones Generales creó su propio servicio racial. « $L a$ represión de los israelitas en virtud de las leyes y ordenanzas que acababan de ser

\footnotetext{
${ }^{19}$ Para información más desarrollada sobre todas estas cuestiones y una bibliografía precisa, puede verse Jean-Marc Berlière, Polices des temps noirs.

20 « Police Judiciaire », la Policía Judicial. Organismo diferenciado de la Policía Administrativa desde los tiempos de la Revolución. Nota de Alejandro Pérez-Olivares.
} 

francesas

dictadas por el gobierno de Vichy y los alemanes», como explicó a la comisión de depuración uno de sus inspectores, fue confiada a la sección tercera, la de "judíos y extranjeros no terroristas". Se puso a una decena de inspectores a cargo de las investigaciones, «una tarea delicada pues suscitaba muchos casos de conciencia». «Durante varios meses» explica un jefe de grupo de esta sección tercera de las IG, «tuve que trabajar en centenares de investigaciones sobre las personas señaladas en las notas de la Dirección de asuntos judios o en cartas anónimas, que no eran conformes a la legislación en vigor, sin tener que intervenir directamente en los casos de investigaciones judiciales o arrestos: estos estaban reservados a un grupo especial de vía pública tras recibir el parecer o decisión de la Dirección de Asuntos judíos». Este «grupo especial de vía pública»-una innovación estrictamente inaudita para un servicio político- no se conformaba con ir a detener a los judíos denunciados. Con la ayuda de controles inesperados, "pedían los papeles" en la vía pública buscando israelitas infringiendo la ley francesa o las ordenanzas alemanas. Una quincena de inspectores operaba en las estaciones, el metro, los cafés y otros lugares públicos, a menudo acompañados de refuerzos temporales del Parti Populaire francés, de señaladores judíos, de alemanes del servicio de "IV B" de la SIPO, y realizaron así varios miles de arrestos bajo la dirección de un inspector principal con reputación de "come judíos".

En cuanto a la policía municipal uniformada, que desempeñaba un papel esencial en las redadas, la misma no desatendió sin embargo las infracciones respecto a la legislación antijudía $\mathrm{y}$, las debidas a «no respetar las horas legales de salida»o «disimulo de la estrella». Los guardianes de la paz y las Brigadas especiales de intervención contribuyeron a llenar las furgonetas policiales que llevaban a Drancy los resultados de la caza diaria. De este modo, la competencia entre las "policías de ocasión", la voluntad de Bousquet de atribuir esas misiones a la policía oficial, explican en parte las derivas y la ruptura que la política de colaboración deseada por Vichy contribuyó a precipitar.

\section{LA POLICÍA «A LA HORA ALEMANA»: EL ENGRANAJE DE LA COLABORACIÓN}

La policía, atrapada en los hábitos de pre-guerra, del legalismo, la disciplina, la cultura profesional y sus intereses corporativos y materiales, fue también la policía de la 

francesas

política de colaboración que el gobierno francés seguía queriendo obtener desesperadamente, y que llevó a la policía francesa a realizar las tareas del ocupante a cambio de una autonomía administrativa y de un reconocimiento de soberanía que Vichy estaba dispuesto a comprar a cualquier precio. Este principio de colaboración de las policías se interrumpió, a principios de mayo de 1942, durante el encuentro de Bousquet con Heydrich en París.

Según las partes, lo que estaba en juego era muy diferente. Para el gobierno francés, se trataba de obtener el reconocimiento de una apariencia de soberanía en zona ocupada. Los nazis, a cambio del abandono de su tutela, esperaban una colaboración más eficaz de la policía francesa. Pensaban asegurar así a buen precio -más eficacia, menos reacciones anti-alemanas de la población, reducción de unos efectivos muy necesarios a partir del ataque de la URSS-, la protección de sus tropas y las entregas de judíos necesarias para la aplicación de la "solución final" en Europa oriental, al tiempo que comprometían a la policía francesa: lo que constituía un buen medio de conseguir su vinculación y la mejor garantía de su eficacia. Después de la muerte de Heydrich se retomaron las negociaciones, a petición de Laval, entre Bousquet y el general de las S.S. Oberg, jefe de todas las policías alemanas para la Francia ocupada. Los franceses hacían reclamaciones como muestra una carta que Bousquet dirigió a Oberg: "Usted conoce bien la policía francesa. Tiene sus defectos, pero también sus cualidades. Estoy convencido que reorganizada y con nuevas bases y enérgicamente dirigida, podría prestar los más grandes servicios. Usted ya ha podido constatar la eficacia de su acción en numerosos asuntos. Estoy seguro de que puede hacer aún más."

Como indica Robert Paxton: «Esta politica de presencia administrativa, reivindicada sin cesar, dio lugar a un activismo antijudio ${ }^{21} \gg$. Las redadas contra los judíos del verano del 42 estuvieron completamente a cargo de la policía y gendarmería francesas: una preocupación por salvaguardar la soberanía francesa que le fue reconocida a Bousquet en su proceso de 1949. El 8 de agosto de 1942, los diferentes puntos del acuerdo negociado se hicieron públicos en una reunión a la que se invitó a los prefectos regionales e intendentes de policía. En el discurso pronunciado en esta

\footnotetext{
${ }^{21}$ Robert Paxton, "La spécificité de la persécution des juifs en France", Annales ESC, 3 (1993), 605-619.
} 

francesas

ocasión, el general de las S.S. insistió en el nuevo rol de la policía francesa: "[ésta] debe bajo su propia responsabilidad contribuir a la lucha contra nuestros enemigos comunes: comunistas, terroristas, saboteadores, en coordinación con las fuerzas de la S.S. y de la policía bajo mis órdenes. [...] En la Europa nueva, el malhechor criminal y político no podrá alterar el trabajo de corrección de los pueblos." La policía francesa colaboró con esta gran obra "comunicando todas las informaciones útiles" y "combatiendo ella misma bajo su propia responsabilidad [...] contra los comunistas, terroristas y saboteadores aplicando todos los medios a su disposición." Como precio de esta colaboración, ya no tuvo que designar rehenes y las personas detenidas no fueron objeto de represalias. Los policías estaban mejor armados y se crearon nuevos $\mathrm{GMR}^{22}$ así como escuelas para aumentar su "rendimiento" y su "poder de choque".

El 13 de agosto, la copia de una nota de Oberg precisando las condiciones de la autonomía de la policía francesa fue remitida por Bousquet a los prefectos regionales: "Los alemanes se comprometen a dejar de emitir órdenes directamente a los funcionarios subalternos de la administración francesa. En ningún caso, deben las operaciones ser emprendidas en común por las policías alemana y francesa. Las medidas de represalias colectivas y especialmente el fusilamiento de rehenes se suspenden. La justicia francesa tiene el derecho exclusivo de juzgar según la ley francesa a los franceses culpables de delitos contra el derecho común o de delitos políticos que no se dirijan exclusivamente contra el ejército o las autoridades de ocupación". Este texto venía acompañado de una carta del Secretario General en la que se señalaba «el carácter ejemplar que debe en adelante revestir la represión de las maniobras antinacionales». El mismo día, en otra carta, dirigida esta vez a los prefectos departamentales, el propio Bousquet insistía en que la obligación de obtener resultados competía a partir de aquel momento a la policía francesa: "Comprenderéis que si la nota del General Oberg da a la policía francesa, tanto en el plano moral como en el material, medios de acción que no tenía hasta ahora, es importante que, mediante acciones incrementadas y los resultados que se obtengan, los servicios de policía den prueba de su eficacia real. Os corresponde dar el impulso vigoroso cuya total necesidad veis, como yo, en las circunstancias presentes."

\footnotetext{
22 "Groupes Mobiles de Réserve", unidades paramilitares creadas por el gobierno de Vichy. Nota de Alejandro Pérez-Olivares.
} 
Estos eran los engranajes y el marco oficial de la colaboración a la que se condujo a la policía y que Bousquet presentó en su memoria de defensa de agosto de 1948 como "un acto de salvaguardia y defensa de los intereses franceses". La parte alemana encontraba en esto ventajas más claramente perceptibles: "La gran ventaja es que nunca di órdenes a la policía francesa" dijo Oberg en una declaración de febrero de 1946. Su adjunto, Knochen, volvió sobre ello en septiembre de 1948: «Si pudimos tener en Francia una policía menos numerosa [que en Bélgica y Holanda] es porque existía un gobierno establecido y una policía oficial en lugar de una policía auxiliar como en los otros países» ${ }^{23}$.

\section{EL NAUFRAGIO...}

La creación, en enero del 43, de la «Milicia francesa» de la que Pétain afirmó, el 29 de abril, que "[debía] constituir la fuerza indispensable para realizar la lucha contra las fuerzas ocultas" y "ser encargada de todas las misiones de vanguardia, especialmente la relativas al mantenimiento del orden [...] en la lucha contra el comunismo", mostraba al mismo tiempo la radicalización del régimen y el fracaso de la solución Bousquet. Desde el mes de mayo de 1943, y a pesar de la fuerte impresión que había producido el secretario general de la policía en Himmler, los alemanes abordaron la eventualidad de reemplazarlo y dar a la Milicia ("un movimiento que presenta afinidades profundas con el movimiento S.S. y capaz de dar un nuevo impulso a las fuerzas francesas del orden") el mando de la represión y el mantenimiento del orden, para lo que bastaba con los medios normales de la policía tanto más por cuanto la actividad de la policía comenzaba poco a poco a disminuir. A finales de diciembre de 1943, R. Bousquet fue reemplazado por J. Darnard en la dirección de lo que se convirtió en la "Secretaría General de Mantenimiento del Orden". El decreto del 10 de enero de $1944^{24}$ precisaba que "por delegación del Jefe de Gobierno, Ministro de Interior, M. Joseph Darnand, Secretario General de Mantenimiento del Orden, tiene autoridad sobre la totalidad de las fuerzas de policía, cuerpos y servicios, que aseguran la seguridad pública y la seguridad interior del estado".

\footnotetext{
23 Declaración de Helmut Knoccehn, septiembre de 1948, en el expediente de instrucción de René Bousquet. El personal de policía asignado a la ocupación de Francia nunca pareció superar los 3000.

${ }^{24}$ Journal officiel de l'Etat Français, 20 enero de 1944.
} 
Este dominio de la Milicia sobre el aparato policial permitió seguidamente a los responsables de la policía justificar su actitud por la voluntad de retrasar o impedir la solución de la milicia: al fin y al cabo, la policía provocaba menos destrozos y mostraba más humanidad. Sin embargo, antes de esta deriva totalitaria de 1944, y sin tener en cuenta el Estado-milicia que fueron los últimos meses de la ocupación o los crímenes perpetrados por las policías supletorias al servicio de la Gestapo, las inusuales misiones que se le habían confiado y que asumió, las prácticas que siguieron, habían transformado profundamente el mundo policial muy alterado por la multiplicación de efectivos. Estas rupturas -profesionales, culturales y deontológicas, el naufragio de los principios republicanos que reflejaban, marcaron de forma duradera a la policía y la percepción que la sociedad tenía de la misma.

\section{... Y SUS CAUSAS}

La policía de la Ocupación estuvo caracterizada grandes cambios en el reclutamiento y las motivaciones, nuevas derivas de las misiones y los métodos. El que tantos jóvenes policías -sin ideología y sin un odio particular- mostraran un celo en ocasiones criminal, se debió a que ya no había ni se aplicaban los frenos del aprendizaje, la transmisión de los veteranos, los consejos de moderación, la idea de «lo que no se hace», las órdenes que no se aplican. Llevados a acorralar a personas cuya sola culpa era haber sido legalmente privados del derecho a la existencia, la policía llegó claramente a límites deontológicos que pocos agentes sin embargo tuvieron el valor de no traspasar. Ante una legislación que criminalizó la pertenencia religiosa, filosófica o política, fueron pocos los que tuvieron ese reflejo de desobedecer, algo que sintieron de forma natural sus colegas del servicio de extranjeros de la policía de Nancy ${ }^{25}$. Pero mientras que Jules Jeanneney, presidente del Senado, podía escribir "Desapruebo la ley sobre el estatus de los judios, por cuanto tiene de contraria a la justicia, al respeto de la persona humana, a la tradición francesa [...] es no obstante la ley. Se le debe obediencia", habría algo de hipocresía, incluso injusticia, en reprochar más a los funcionarios subalternos haber aplicado -bajo órdenes- una legislación redactada en sus

\footnotetext{
${ }^{25}$ Jean-Marie, Muller, Désobéir à Vichy. La résistance civile de fonctionnaires de police (Nancy, PUN, 1994).
} 
mínimos detalles por la alta función pública, fríamente comentada por los más eminentes juristas del Consejo de Estado.

¿Podemos decir, sin embargo, como Karl Oberg, jefe de todas las policías alemanas presentes en Francia, que "La policía francesa [fue] diligente y llena de buena disposición? "La policía", tanto en 1940 como hoy en día, es en realidad múltiple y diversa. Sus actos bajo la ocupación reflejaron en su diversidad y contradicciones, las diversidades y contradicciones de la sociedad francesa aún más matizadas por la cronología y la geografía. La confusión se mantuvo o se incrementó por esta evidencia: tanto en la Seguridad Nacional como en la Prefectura de Policía, la jerarquía policial de Estado Francés estaba constituida por hombres que habían servido durante la Tercera República hasta en los gabinetes ministeriales socialistas. Esta continuidad contribuyó a entremezclar las cartas y jugó un papel determinante en la actitud de los policías que no fueron sistemáticamente "servidores [de los nazis] siempre a la búsqueda de éxitos cotidianos" como algunos han escrito ${ }^{26}$. La requisitoria del Comisario del Gobierno en el proceso de Amédée Bussière insiste en las consecuencias perversas de esta continuidad: "En semejante puesto, un alemán o un miliciano claramente del lado de los alemanes, hubieran sido menos capaz de hacer daño pues todos los funcionarios de la Prefectura de policía hubieran saboteado instrucciones revestidas con esa firma, en cambio el nombre de Bussière, funcionario francés con una trayectoria de altos cargos prefectorales, pudo dejar desamparados a algunos"27.

¿Por qué los policías obedecieron mayoritariamente las órdenes y cumplieron esas misiones, cuya naturaleza no podían dejar de percibir? Los impulsos de dicha actitud fueron diversos y múltiples. En esto influyeron factores como las ambiciones y rivalidades personales o profesionales, la lentitud burocrática, el peso de las rutinas y hábitos y los contenciosos administrativos. La competencia de las estructuras parapoliciales aplicada por los nazis o Vichy, con los ultras de la colaboración, provocó, como hemos visto, una reacción de defensa corporativista con muchas consecuencias. Frente a los no profesionales, demostraban su competencia, su profesionalidad, además con la buena conciencia o la ilusión de estar evitando lo peor.

\footnotetext{
${ }^{26}$ Para este tipo de enjuiciamiento definitivo y sin matices, remitimos por ejemplo a Maurice Rajsfus, $L a$ Police de Vichy. Les forces de l'ordre françaises au service de la Gestapo (París, Le Cherche midi, 1995).

${ }^{27}$ Archivos nacionales, serie Z6, expediente Amédée Bussière.
} 

francesas

Esta preocupación de defender, frente a la inusual competencia, un honor profesional, un oficio, un "saber hacer" cuestionado por la pérdida del monopolio del uso legítimo de la violencia, explica una curiosa reacción que podemos comparar con el síndrome del «puente sobre el rio Kwai». Hannah Arendt, en su reflexión sobre los orígenes del totalitarismo, recordó la admiración de la policía francesa de los años treinta por la Gestapo y la eficacia de sus métodos: en la rivalidad que les oponía a la otra «mejor policía del mundo», es posible que los policías empujados por un celo u orgullo profesionales de desastrosas consecuencias, desearan probar el valor de la tradición policial francesa. No podemos dejar de considerar los vínculos personales de solidaridad y estima profesional, a veces amistad, que existían antes de la guerra entre policías franceses y alemanes dentro de este organismo policial anticomunista constituido por la Commission internationale de police criminelle, antecesor de Interpol, creado en Viena en 1923, que los nazis heredaron tras el Anschluss y que fue presidido por Heydrich y después Kaltenbrunner.

Hay aún otros factores que pueden explicar una actitud que es preciso, por otro lado, matizar de acuerdo con la cronología, la geografía y los individuos ¿Qué pensar del último llamamiento a sus brigadas de un hombre como F. Buffet, director de la Policía de Seguridad y curtido en las «brigadas del Tigre»: «Más que nunca el orden público se encuentra amenazado? Más que nunca los malhechores se disfrazan, para ocultar sus fechorías, con una etiqueta política o patriótica [...]. Es uno de los vuestros, el que os garantiza, a todos vosotros que seguís lealmente en la línea correcta, la seguridad total para vosotros y vuestras familias. Es uno de los vuestros el que os dice: haced vuestro deber, y no temáis nada de nadie.» En estas ocasiones es cuando muestra sus últimas consecuencias la cultura profesional -especialmente la "cultura de obediencia"- que constituye la esencia misma de la policía y desarrolla en su seno una irresponsabilidad que toda la historia policial contribuye a reforzar. Más que el temor a las represalias o la pérdida de empleo, es esta cultura la que explica que muchos policías hayan perseguido a personas a las que todo-según sus criterios- las asemejaba con delincuentes comunes y las situaba fuera de la ley que ellos están esencialmente encargados de hacer respetar. La disciplina, la obediencia eran las cualidades esenciales que se había querido desarrollar en ellos. Éste fue el precio a pagar por un reclutamiento 
esencialmente militar, y una formación dirigida a la disciplina y el respeto de la consigna.

La legalidad del Estado francés, la personalidad de su jefe, tuvieron mucho peso: afectaron durante mucho tiempo a la visión que una mayoría de los policías pudo tener de una acción que parecía además situarse en la continuidad de los finales de la Tercera República. Al seguir cumpliendo las mismas tareas bajo la dirección de los mismos jefes, en referencia a los mismos textos, contra las mismas categorías de personas, muchos policías no percibieron gran diferencia entre los comienzos de Vichy y el fin de la República. ${ }^{28}$ Un número no despreciable de policías fueron más sensibles a las consignas xenófobas y anticomunistas de la propaganda de Vichy pues estos fueron sentimientos exaltados a finales de la década de 1930. El anticomunismo, debido en gran parte a un sangrante conflicto que se remonta a los años 20 , fue reactivado por la actitud de los comunistas: su retorno posterior al pacto germano-soviético, las acciones de sabotaje perpetradas en las fábricas de guerra en nombre del derrotismo revolucionario de la primavera de 1940, y luego, los atentados cometidos contra policías a finales de 1941 exacerbaron claramente una actitud que la Guerra Fría justificó $a$ posteriori.

Además, la visión impregnada de xenofobia habitual desde la época del caso Dreyfus no llegó nunca a desaparecer. En cuanto al celo desplegado por los funcionarios franceses contra los judíos extranjeros, se percibe el peso de los hábitos adquiridos durante los años treinta, pero también las prácticas elaboradas con la aplicación durante la Tercera República de legislaciones cada vez más restrictivas y medios de control cada vez más estrechos, que ejercieron un papel claro en el desarrollo de una cultura xenófoba o antisemita en las filas policiales. Es posible que los policías a cargo de la gestión y vigilancia de más de 500.000 extranjeros les hicieran sufrir la impaciencia de la población además de sus propios rencores. Durante ese tiempo, la administración perfeccionaba un sistema de control más eficaz cuyo componente central era un Fichero central, verdadera mina de informaciones de tipo administrativo o judicial que los representantes de la mayoría de policías extranjeras estudiaron. La actitud de parte de la

\footnotetext{
${ }^{28}$ Recordamos esta frase de Hannah Arendt: «Nosotros exigimos que un ser humano sea capaz de distinguir el bien del mal, incluso cuando solo tiene para guiarse más que su propio juicio», en Eichman à Jérusalem. La banalité du mal (París, Gallimard, 1991 [1963]), 471.
} 
policía durante la ocupación encuentra su explicación y últimas consecuencias en la conjunción de este perfeccionismo administrativo, un "amor propio" profesional mal entendido, un sentimiento xenófobo ampliamente compartido y de alguna forma promovido por la aplicación de una legislación minuciosa. Sin embargo, el arresto de policías a manos de otros policías - el martirio, la deportación de muchos de ellosexpresan todas las contradicciones de una sociedad despedazada.

\section{¿OTRAS OCPIONES?}

Adrien Tixier, Ministro de Interior durante la Liberación, recordaba en diciembre de 1944 los informes contradictorios que recibía de distintos Comités departamentales de liberación sobre un mismo funcionario. Según la fecha en la que hubiera estado en ejercicio en el departamento, se presentaban o bien como dedicación y compromiso admirables en la Resistencia o, al contrario, como un policía diligente en su obediencia a las órdenes de Vichy. El problema de la actitud de los policías es complejo, pues está vinculado a numerosos parámetros y la cronología no es el menos importante entre ellos. El doble juego era un elemento indispensable: para tener acceso a informaciones importantes, poder informar a la Resistencia, un policía debía adoptar una actitud que le hiciese incuestionable. Las redes de resistencia eran muy conscientes de esto e imponían a los policías de la resistencia seguir en sus puestos incluso participar en la represión para poder sabotearla mejor. Pero esta apariencia provocó muchas dudas e incomprensión. Incluso costó la vida a numerosos policías abatidos en una limpieza extrajudicial basada solo en apariencias. Esto debe ser un llamamiento a la prudencia y a apreciaciones matizadas cuando abordamos la cuestión de la resistencia policial, tema sensible donde los haya y oscurecido además por mitos y leyendas.

Las estadísticas facilitadas en 1947 por el Ministerio de Interior -"1048 miembros de la Seguridad deportados, de los cuales 300 no volverían, 373 fusilados o muertos en combate, 35 muertos bajo tortura, 779 encarcelados o internados, 2467 sancionados"- son impresionantes. Estas cifras permiten escribir que "la policía pagó un elevado precio por la ocupación. Es el cuerpo del Estado que contabilizó mayor número de fusilados, deportados, -muchos de ellos muertos en los campos-, apresados, internados y apartados." No deben dispensarnos de plantear la cuestión de la actitud de la mayoría de los policías. Si bien la Resistencia dentro de la policía es una realidad, hay 
que tener cuidado de no confundir la pasividad creciente del mundo policial a partir de 1943 con el mito creado por la historiografía oficial. Tras haber ignorado durante mucho tiempo la propia participación de policías franceses en operaciones atribuidas erróneamente solo a los nazis, a la «Gestapo» o a algunos franceses desviados, la administración reconoció "ovejas negras" cuya actividad criminal sirvió, sobre todo, para ocultar la participación colectiva de la institución en la política represiva de Vichy al servicio del ocupante en las condiciones que hemos mencionado. Los crímenes de una "minoría de policías como los de las Renseignements généraux y las BS [...] totalmente sometidos al enemigo, colaborando de forma entusiasta y de mala ley en la caza de patriotas ", sirven para destacar la dignidad de "la gran mayoría de policías [que] obedecian a su conciencia y por ello practicaban una resistencia individual y no aplicaban las órdenes que les daban de Vichy de detener a los miembros de la resistencia, a los judios o a los STO". ${ }^{29}$

La resistencia policial es un mito, en el sentido de que, aunque hubo una resistencia por parte de los policías más amplia de lo que se cree y se dice -también sería falso e injusto negarlo-, ésta fue esencialmente un compromiso individual. Pero en el seno de la Prefectura de Policía, donde se celebra cada año el levantamiento de agosto de 1944, los movimientos de resistencia fueron minoritarios y su papel discreto hasta el verano de 1944. Si bien debemos relativizar la resistencia policial, hubo en cambio pocos policías que se sumaran a las ideas y a los partidos de la colaboración. Colaborando de mala gana con los policías «de ocasión»y las oficinas paralelas, reprobando el celo y fanatismo de algunos de sus colegas, marcando su repugnancia por los milicianos, muchos policías dieron prueba de pasividad en el cumplimiento de tareas que muchos de ellos solo efectuaban a regañadientes.

Evitaremos igualmente olvidar el papel de los centenares o millares de policías anónimos (y muy discretos al respecto, incluso en la postguerra: ¡nunca es bueno decir que hemos saboteado las consignas o desobedecido las órdenes!) en la «paradoja

\footnotetext{
${ }^{29}$ Palabras de los presidentes de la Unión de antiguos combatientes de la Prefectura de Policía (UACPP) y de la Federación de antiguos combatientes y resistente de la Prefectura de policía (FACRPP) respectivamente. Citadas en «Ils se souviennent» número especial -"Libération de Paris, 50e anniversaire"- de la revista Liaisons, editada por la PP dedicada a la "Commémoration du soulèvement de la Préfecture de police", pp. 36-37. Las siglas STO hacen referencia al Service du Travail Obligatoire, la oficina de reclutamiento obligatorio para trasladar forzadamente a trabajadores que debían contribuir al "esfuerzo de guerra". Nota de Alejandro Pérez-Olivares.
} 

francesas

francesa», destacada por el historiador belga Maxime Steinberg. Una paradoja en el hecho de que las 3/4 partes de la población judía en Francia evitaron la deportación (frente a solo 1/4 en los países bajos, la mitad en Bélgica y Noruega) a pesar de que el Estado francés había puesto a la policía francesa a disposición del ocupante ${ }^{30}$. Es innegable que en las redadas contra los judíos y, más claramente aún, en la búsqueda de refractarios del STO, muchos policías no solo mostraron poca diligencia e iniciativa, sino que sin lugar a dudas, una parte de ellos, imposible de cuantificar, intentó sabotear estas misiones avisando a los afectados, a riesgo de encontrarse con la incredulidad, la incomprensión o la resignación de las víctimas, de ser denunciados por compañeros, porteros, vecinos, testigos, o los alarmados por la repetición de los fracasos. El caso de los policías del servicio de extranjeros de la policía de $\mathrm{Nancy}^{31}$ no es, como muestra Ivan Ermakoff ${ }^{32}$, excepcional. Son abundantes las pruebas de fugas gracias a los policías durante las redadas. Es el caso de las redadas del 16 y 17 de julio en París cuyos resultados fueron inferiores, casi la mitad, de lo que esperaba el director de la Policía general de la Prefectura de Policía. Los alemanes atribuyeron este «fiasco» relativo a las huidas masivas causadas por los policías. Esto explica las precauciones que se tomaron en las operaciones posteriores. Desde el 22 de agosto, en sus instrucciones a los prefectos para la realización de redadas previstas el 26 en zona no ocupada, Bousquet insiste: "Ustedes no dudarán [...] en señalar a los funcionarios cuya indiscreción, pasividad o mala voluntad complicase su tarea". En París, la Prefectura de Policía aplicó una serie de medidas destinadas a impedir la repetición de esas fugas y evitar cualquier riesgo de complicidad.

La permanencia de los hombres, la lógica de continuidad que parece marcar la historia de la policía hasta la ocupación no debe por tanto disimular numerosas rupturas fundamentales e irreversibles. La depuración que acompaña a la Liberación, los ajustes

\footnotetext{
30 «Le paradoxe français dans la Solution finale à l'Ouest» Annales. Économies, Sociétés, Civilisations. 48e année, $\mathrm{N}^{\circ} 3$, 1993. pp. 583-594. Añadiremos a este artículo pionero la obra del rabino Alain Michel, Vichy et la Shoah. Enquête sur le paradoxe français (Jerusalén, Elkana, 2015, 2e édition) .

31 Jean-Marie Muller, op. cit..

32 Ivan Ermakoff, «Police et arrestations», en « Pour une micro histoire de la shoah », Le Genre Humain, $52(2012)$.
} 
de cuentas de la que fue el teatro y las luchas de las que fue objeto constituyen otra ruptura importante ${ }^{33}$.

\section{REFLEXIONES FINALES: LA HORA DE LAS CUENTAS}

«Si bien el gobierno quiere proceder [...] a las eliminaciones necesarias [...] no hay en ningún modo la intención de hacer tabla rasa de la gran mayoría de servidores del Estado, la mayor parte de los cuales, durante los terribles años de ocupación y usurpación, intentaron ante todo servir lo mejor que pudieron a lo público. La denigración de tales o cuales miembros o de tal o cual categoría de la administración es algo fácil, pero con demasiada frecuencia injusto o exagerado ${ }^{34} \gg$. A pesar de estas palabras realistas del general De Gaulle, muy consciente de la necesidad de mantener en pie una administración en funcionamiento y garante del orden, no era imaginable - a pesar del oportuno giro habido en el verano de 1944 - que la policía que, durante cuatro años había representado la parte más visible, más inmediatamente perceptible de la complicidad con el ocupante, no fuese depurada, aunque fuese en contra de todas las tradiciones de su historia y de la cultura funcionarial de obediencia integrante de la misma.

La depuración - por su violencia, duración y resultados- supone una verdadera revolución cultural en un ámbito policial que nunca más volvió a ser el mismo tras haber visto en el transcurso de varias semanas la inversión de los códigos en los que se fundaba su existencia, y haber saboreado con embriaguez los encantos de prácticas hasta entonces prohibidas: huelga insurgente, denuncias de compañeros, arrestos de jefes... Es difícil medir lo que representó este vuelco de los valores integrantes de tantas leyes fundamentales de la profesión. A los ojos de los encargados de la depuración, un agente disciplinado se convertía en un agente "servil", el celo profesional se asimilaba a una "traición." Buenas notas, recompensa, iniciativa, un ascenso constituían motivos de sanción. Por otro lado, castigos, notas mediocres, esperas, pasividad, inacción, fallos profesionales, no respeto de los reglamentos, desobediencia, indisciplina pasaban a ser

\footnotetext{
33 Sobre la depuración de la policía, sus mecanismos, resultados, remitimos a Jean-Marc Berlière, Policiers français sous l'occupation (París, Perrin, 2009).

${ }^{34}$ Charles De Gaulle, Discours et messages, t.1, 25 julio 1944 (Plon, 1970), 432.
} 

francesas

certificados de resistencia, incluso títulos de gloria que justificaron ascensos espectaculares.

Si la ocupación planteó con intensidad el problema de la cultura de obediencia que hasta entonces caracterizaba a la policía y daba base a su esencia, la depuración sacó a la luz sus contradicciones. Mientras que el gobierno, por ordenanza del 28 de noviembre de 1944, había previsto excusas absolutorias para los funcionarios que hubiese actuado obedeciendo órdenes, la depuración tanto administrativa como judicial se dispuso a demostrar que "el celo y la iniciativa" eran "elementos constitutivos del crimen en el caso de un policía". El comisario del gobierno que reclamaba -y obtenía- la cabeza de un inspector de las BS exclamando -"¿Recibió usted órdenes? Pues bien, jhay ordenes que no se cumplen!"- ¿era consciente de que atacaba la base de toda policía?

Los policías descubrieron con dolorosa sorpresa que una "apariencia de legalidad puede cubrir actos ilegítimos": descubrimiento que conllevó la negación de la obediencia ciega, la disciplina, la neutralidad constituyente de la esencia de toda policía. Este cambio de reglas de juego suscitó la incomprensión de los interesados - "Si cuando un jefe te da una orden tú te preguntas: ¿debo cumplirla?, ya nada se sostiene"- y la preocupación de los policías que siguieron en ejercicio y que pidieron explícitamente ser "protegidos contra las medidas que puedan tomarse contra ellos por los futuros gobiernos por haber ejecutado órdenes del gobierno actual." El celo y la obediencia que habían hecho hasta entonces que la policía fueran un instrumento y una defensa esenciales de los regímenes sucesivos, se convirtieron en culpas que se corría el riesgo de expiar intensamente. Por ese motivo, la depuración constituyó un seísmo en una institución que hasta entonces había estado a salvo de convulsiones políticas por esta ley no escrita, pero de sentido común, que tanto la Tercera República como Vichy respetaron, que establecía que la policía no se depura para no debilitar su dedicación respecto al nuevo régimen. Esta transgresión rompía un recurso del Estado. Al romper el pacto que vinculaba a los policías con el poder, la transgresión debilitó el poder político: un hecho que la Cuarta República no tardó en experimentar a su propia costa, especialmente en la primavera de 1958 cuando la policía se dejó pasivamente ser presa del poder por parte de Charles de Gaulle contra una república que no tenía ninguna gana 
de defender ${ }^{35}$. Al haber descubierto el atractivo de la conspiración política, de la insubordinación, de la huelga, de la insurrección, del arresto y enjuiciamiento de los superiores jerárquicos, la policía no volvería a ser nunca como antes ${ }^{36}$.

Sin embargo, la reflexión beneficiosa que habría permitido la cultura de "la vergüenza de los años negros" fue ocultada por una historia legendaria que el general De Gaulle había contribuido a fundar y cuyas consecuencias están aún claramente sin medir. Si añadimos a esto la proliferación de los servicios especiales, de policías paralelas operando en ámbitos y condiciones jurídicas mal definidos, la multiplicación de procedimientos excepcionales y derogatorios respecto a las condiciones habituales de contratación y promoción, las misiones y prácticas de todo tipo salvo democráticas, presentimos que la Cuarta y la Quinta República tuvieron ocasión de experimentar en otras circunstancias, las derivas engendradas por la guerra y exacerbadas por los conflictos coloniales.

\section{BIBLIOGRAFÍA}

Antonowicz, Gilles, L'énigme Pierre Pucheu (Paris, Nouveau-Monde éditions, 2018).

Arendt, Hannah, Eichman à Jérusalem. La banalité du mal (Paris, Gallimard, 1991 [1963]

Baruch, Marc-Olivier, Servir l'Etat français (Paris, Fayard, 1997).

Belin, Jules, Trente ans à la Sûreté Nationale (Paris, Bibliothèque France Soir, 1950)

Berlière, Jean.-Marc, Polices des temps noirs (Paris, Perrin, 2018).

Berlière, Jean-Marc et Liaigre, Franck, Liquider les traîtres (Paris, Robert Laffont, 2007).

Berlière, Jean-Marc, Naissance de la police moderne (Paris, Perrin, 2011).

Berlière, Jean-Marc, Policiers français sous l'occupation (Paris, Perrin, 2009).

Bernert, Philippe, Roger Wybot et la bataille pour la DST (Presses de la Cité, 1975)

Daudet, Léon, La police politique et ses crimes (Paris, 1934) et Magistrats et policiers (Paris, 1935)

\footnotetext{
${ }^{35}$ Para tener una idea del ambiente que reina en el Ministerio de Interior (plaza Beavau) y de la actitud de la Policía en las horas cruciales de mayo de 1958, podemos leer lo que dijo al respecto Roger Wybot, Director de Vigilancia del Territorio. Véase Philippe Bernert, Roger Wybot et la bataille pour la DST (Presses de la Cité, 1975), 450 sq. y Jules Moch, Ministro de Interior Une si longue vie (Robert Laffont, 1976), $511 \mathrm{sq}$.

${ }^{36}$ Para la Cuarta República Cf. Claude Angelli y Paul Gillet, La police dans la politique, 1944-1954 (Grasset, 1967).
} 
De Gaulle, Charles Discours et messages, t.1, 25 juillet 1944 (Plon, 1970), 432.

Ducloux, Louis, Du chantage à la trahison (Paris, Gallimard, 1955).

Ermakoff, Ivan, «Police et arrestations », dans «Pour une micro histoire de la shoah», Le Genre Humain, 52 (2012) .

Groussard, Georges, Service secret 1940-1945 (Paris, La Table Ronde, 1964)

Michel, Alain Vichy et la Shoah. Enquête sur le paradoxe français (Jerusalén, Elkana, 2015, 2e édition).

Moch, Jules, Une si longue vie (Robert Laffont, 1976)

Muller, Jean-Marie, Désobéir à Vichy. La résistance civile de fonctionnaires de police (Nancy, PUN, 1994).

Paxton, Robert, "La spécificité de la persécution des juifs en France", Annales ESC, 3 (1993), 605-619.

Rajsfus, Maurice, La Police de Vichy. Les forces de l'ordre françaises au service de la Gestapo (París, Le Cherche midi, 1995). 